\title{
Ativismo Judicial e a Implantação do Programa Família Acolhedora no Estado de Mato Grosso do Sul
}

\author{
Judicial Activism and the Implementation of the Foster Care Program in the \\ State of Mato Grosso do Sul \\ Activismo Judicial y la implementación del Programa de Acogimiento Familiar \\ en el Estado de Mato Grosso do Sul
}

\author{
Michel Canuto de Sena ${ }^{1}$ \\ Fernando Moreira Freitas da Silva² \\ Heitor Romero Marques ${ }^{3}$ \\ Paulo Roberto Haidamus de Oliveira Bastos ${ }^{1}$
}

Recebido em 29/04/2020; revisado e aprovado em 26/05/2020; aceito em 17/07/2020.

DOI: http://dx.doi.org/10.20435/inter.v21i4.3035

\begin{abstract}
Resumo: O presente artigo objetiva discutir a inércia dos municípios do Estado de Mato Grosso do Sul na implementação do Programa Família Acolhedora, em total descumprimento ao Estatuto da Criança e do Adolescente. Por meio de pesquisa exploratória, a partir dos dados disponíveis no site do Tribunal de Justiça do Estado de Mato Grosso do Sul, analisa-se o estágio atual de implementação do programa no Estado, que, conforme resultados apurados, apresenta um baixo grau de efetividade. Na sequência, a partir de revisão bibliográfica, estuda-se o ativismo judicial como uma possível solução à inércia dos Poderes Executivo e Legislativo, observando os seus pontos favoráveis e contrários. Ao final, conclui-se que, após 10 anos de vigência da lei que institui o Programa Família Acolhedora, Lei n. 12.010, de 3 de agosto de 2009, apenas 12,65\% dos municípios do Estado de Mato Grosso do Sul o implementaram ou estão em fase de implementação. Para garantia da sua efetividade e da integral proteção aos direitos da criança e do adolescente, propõe-se que o Poder Judiciário determine que os municípios apresentem um plano de ação para a sua implementação. Em caso de inércia, deve ser fixada multa. Caso ainda persista a mora, cabe ao próprio Poder Judiciário implementá-lo às expensas do Poder Executivo.
\end{abstract}

Palavras-chave: Família Acolhedora; Estado de Mato Grosso do Sul; ativismo judicial.

Abstract: This article aims to discuss the inertia of the municipalities of the State of Mato Grosso do Sul in the implementation of the Foster Care Program, in total non-compliance with the Statute of the Child and Adolescent. Through exploratory research, based on data available at the Mato Grosso do Sul State Court of Justice site, we analyze the current stage of implementation of the program in the State, which, according to results, presents a low degree of effectiveness. Then, from a bibliographical review, we studied judicial activism as a possible solution to the inertia of the Executive and Legislative Powers, observing their favorable and opposite points. In the end, we concluded that after 10 years of effectiveness of the law establishing the Foster Care Program, Law n. 12.010, of August 3rd, 2009, only 12.65\% of the municipalities in the State of Mato Grosso do Sul have implemented it or are in the implementation phase. To guarantee its effectiveness and full protection of the rights of children and adolescents, we proposed that the Judiciary determines that the municipalities submit an action plan for its implementation. In case of inertia, a fine should be set. If the delay persists, it is up to the Judiciary itself to implement it at the Executive Power's expense.

Keywords: Foster Care; State of Mato Grosso do Sul; judicial activism.

Resumen: Este artículo tiene como objetivo discutir la inercia de los municipios del Estado de Mato Grosso do Sul en la implementación del Programa de Acogimiento Familiar, en completa violación del Estatuto de la Niñez y de la Adolescencia. A través de una investigación exploratoria, a partir de los datos disponibles en el sitio web de la Corte del Estado de Mato Grosso do Sul, se analiza la etapa actual de implementación del programa en el Estado, que, según los resultados, tiene un bajo grado de efectividad. A continuación, a partir de una revisión bibliográfica, se estudia el activismo judicial como una posible solución a la inercia de los poderes Ejecutivo y Legislativo, observando sus puntos favorables y contrarios. Al final, se concluye

\footnotetext{
${ }^{1}$ Universidade Federal de Mato Grosso do Sul (UFMS), Campo Grande, Mato Grosso do Sul, Brasil.

${ }^{2}$ Universidade de São Paulo (USP), São Paulo, São Paulo, Brasil.

${ }^{3}$ Universidade Católica Dom Bosco (UCDB), Campo Grande, Mato Grosso do Sul, Brasil.
} 
que, después de 10 años de vigencia de la ley que establece el Programa de Acogimiento Familiar, Ley n. 12.010, del 3 de agosto de 2009 , sólo el $12.65 \%$ de los municipios del Estado de Mato Grosso do Sul lo implementaron o están en fase de implementación. Para garantizar su efectividad y la plena protección de los derechos de los niños y adolescentes, se propone que el Poder Judicial determine que los municipios presenten un plan de acción para su implementación. En caso de inercia, se debe fijar una multa. Si la mora aún persiste, corresponde al Poder Judicial implementarlo a expensas del Poder Ejecutivo.

Palabras claves: Acogimiento Familiar; Estado de Mato Grosso do Sul; activismo judicial.

\section{INTRODUÇÃO}

O Programa Família Acolhedora foi previsto expressamente no Estatuto da Criança e do Adolescente como uma política pública por meio da Lei n. 12.010, de 3 de agosto de 2009, outorgando a ela preferência em relação ao acolhimento institucional. Objetivou o legislador que as crianças e os adolescentes afastados de suas famílias de origem não fossem enviados para acolhimentos institucionais, mas colocados em famílias, devidamente selecionadas, capacitadas e acompanhadas pelo poder público municipal, com o apoio da União.

Ocorre que, transcorridos aproximadamente 10 anos de sua previsão no Estatuto da Criança e do Adolescente, o serviço de Família Acolhedora ainda é incipiente, descumprindo-se o dever constitucional e infraconstitucional de prioridade absoluta à criança e ao adolescente e justificando a deflagração da presente pesquisa.

Diante da inércia do Poder Executivo, quer por ausência de orçamento, quer por carência de conhecimento acerca de sua existência, poderia o Poder Judiciário intervir para a concretização do programa de acolhimento familiar? Haveria indevida ingerência de um poder sobre o outro, violando-se o princípio constitucional da separação dos poderes? Em se admitindo a atuação do Poder Judiciário, qual seria a extensão dessa intervenção? Poder-se-ia falar em deficit de legitimidade democrática na atuação do Judiciário ao agir nos casos de omissão de outros poderes?

A partir das experiências do Estado de Mato Grosso do Sul na implementação do Programa Família Acolhedora, apresenta-se como objetivo da pesquisa discutir o tema ativismo judicial, buscando responder aos questionamentos supracitados, propondo caminhos para a concretização do direito de crianças e adolescentes ao acolhimento familiar com primazia sobre o acolhimento institucional.

Para a consecução do objetivo proposto, será realizada pesquisa exploratória e revisão bibliográfica, dividindo-se o artigo em três partes. Na primeira, será abordada a previsão legal do Programa Família Acolhedora e o seu atual estágio em nível nacional. Na segunda, pretendese analisar os limites enfrentados pelo Poder Judiciário diante da inércia dos demais Poderes na implementação de tal política pública. Por fim, na derradeira, serão apresentados caminhos possíveis ante a inércia na implantação pelos municípios do Estado de Mato Grosso do Sul do Programa Família Acolhedora.

Somente a partir da concretização dessa fundamental política pública de proteção à infância e à adolescência, no Estado de Mato Grosso do Sul, a qual deve ser tratada com absoluta prioridade, que será possível pensar em desenvolvimento territorial, econômico e social. 


\section{PROGRAMA FAMÍLIA ACOLHEDORA}

O Programa Família Acolhedora foi introduzido pela Lei n. 12.010/2009, que alterou o Estatuto da Criança e do Adolescente, em seu artigo 34, para garantir ao infante afastado de sua família biológica a preferência do acolhimento familiar sobre o acolhimento institucional. Desse modo:

[...] Art. 34. O poder público estimulará, por meio de assistência jurídica, incentivos fiscais e subsídios, o acolhimento, sob a forma de guarda, de criança ou adolescente afastado do convívio familiar.

$\S 1$ ㅇ A inclusão da criança ou adolescente em programas de acolhimento familiar terá preferência a seu acolhimento institucional, observado, em qualquer caso, o caráter temporário e excepcional da medida, nos termos desta Lei.

$\S 2$ ㅇ Na hipótese do $\S 1$ 을 deste artigo a pessoa ou casal cadastrado no programa de acolhimento familiar poderá receber a criança ou adolescente mediante guarda, observado o disposto nos arts. 28 a 33 desta Lei.

§3 A União apoiará a implementação de serviços de acolhimento em família acolhedora como política pública, os quais deverão dispor de equipe que organize o acolhimento temporário de crianças e de adolescentes em residências de famílias selecionadas, capacitadas e acompanhadas que não estejam no cadastro de adoção.

$\S 4$ o Poderão ser utilizados recursos federais, estaduais, distritais e municipais para a manutenção dos serviços de acolhimento em família acolhedora, facultando-se o repasse de recursos para a própria família acolhedora. (BRASIL, 2009, p. 1).

Apesar de a inclusão legislativa datar de 2009, não se pode olvidar que os trabalhos iniciaram-se muito antes dessa data no Município de Camapuã, Mato Grosso do Sul - em 2002, sob a liderança do juiz de direito Deni Dalla Riva ${ }^{4}$-, bem como no Município de Cascavel, Paraná - em 2006, sob a coordenação do juiz de direito Sérgio Luiz Kreuz

Por meio do acolhimento familiar, "as crianças e adolescentes acolhidos recebem cuidados e convivem com as regras próprias da dinâmica familiar, tendo garantido o seu direito à convivência familiar e comunitária" (VALENTE, 2013, p. 107). Assim, a criança ou o adolescente que chega ao acolhimento, geralmente em razão de negligência, maus-tratos ou abusos por parte de sua família de origem, encontrará na família acolhedora a estrutura que precisa para o seu desenvolvimento como pessoa.

Cabe frisar que o próprio Estatuto da Criança e do Adolescente assegura que o programa de acolhimento familiar tem como característica a temporariedade e a excepcionalidade da medida ${ }^{6}$, ou seja, a família acolhedora funciona como um local de passagem da criança e do adolescente, com o escopo de prepará-los para o retorno à família natural, para colocá-los em uma nova família por meio da adoção ou, quando não sendo possíveis as duas situações anteriores, conduzi-los a uma vida independente após atingida a maioridade civil.

Enfatiza-se que jamais servirá a família acolhedora como um alento aos profissionais que militam na seara da infância e da juventude de que a criança e o adolescente estão protegidos

\footnotetext{
${ }^{4}$ Disponível em: https://www.tjms.jus.br/projetos/projeto_familia_acolhedora.php. Acesso em: 10 jul. 2019.

${ }^{5}$ Disponível em: https://www.premioinnovare.com.br/pratica/programa-de-acolhimento-familiar-de-cascavel-pr/ print. Acesso em: 10 jul. 2019.

${ }^{6}$ Ver art. $34, \S 10$, do ECA.
} 
em uma família, podendo o Poder Judiciário dar a prestação jurisdicional no tempo que entender conveniente. Apesar de ser uma família, o acolhimento não é a família definitiva, devendo o Poder Judiciário e os demais atores da rede de proteção promoverem a reintegração familiar ou a colocação em adoção, no menor tempo possível, em cumprimento ao princípio da absoluta prioridade, previsto no artigo 227 da Constituição Federal ${ }^{7}$.

Para que o serviço de acolhimento familiar funcione adequadamente, é necessário que os municípios promovam a regulamentação do programa, bem como empreendam a necessária diligência na seleção das famílias, na sua capacitação e no seu acompanhamento, de modo que sejam minoradas as possibilidades de insucesso do acolhimento em razão dos conflitos surgidos a partir da convivência.

Para os bons resultados do programa, será necessária uma boa estrutura, destacando-se a imprescindibilidade de uma equipe técnica interdisciplinar devidamente preparada e qualificada (KREUZ, 2012, p. 132-3). A ela caberá a especial tarefa de selecionar a família acolhedora, não servindo qualquer uma, mas sim aquela que possua a "vocacionada função para a qual se exige preparo especial e desprendimento, com intuito de oferecer o carinho e cuidado especiais ao assistido" (LÉPORE; ROSSATO; CUNHA, 2018, p. 155).

Embora se trate de atividade que se exija vocação, isso não significa que necessite ser gratuita. Aliás, o próprio Estatuto da Criança e do Adolescente autoriza a remuneração das famílias acolhedoras (Art. 34, §4ㅇำ ${ }^{8}$. Esse é um dos pontos fundamentais para a implementação do programa: a disponibilidade orçamentária para remunerar as famílias que acolhem as crianças e os adolescentes. Ademais, tal remuneração deve ocorrer de forma regular, sob pena de desestimular as famílias acolhedoras, comprometer a credibilidade do programa e, em ultima ratio, conduzir ao fracasso do serviço de acolhimento familiar.

Ocorre que, apesar de devidamente previsto no ECA como uma política pública a ser implementada pelos entes federativos, o Programa Família Acolhedora ainda caminha a passos lentos. Diante dessa inércia do Poder Executivo, a quem é imposto o dever legal de implementálo, surge o debate acerca do ativismo judicial em tal consecução, o que será retratado nas linhas seguintes.

\section{ATIVISMO JUDICIAL}

A terminologia ativismo judicial foi empregada pela primeira vez por Arthur Schlesinger Jr., no ano de 1947, ao comentar os julgamentos da Suprema Corte dos Estados Unidos, embora a própria corte não utilizasse expressamente tal nomenclatura (MORAES, 2012, p. 267-85).

Em um primeiro momento, surgiu com um caráter conservador, atuando a Suprema Corte, de forma proativa, nos interesses de setores mais reacionários, proferindo decisões que deram respaldo à segregação racial (Dred Scott v. Sandford, 1857) e à invalidação das leis sociais em geral (Era Lochner, 1905-1937). Somente a partir da década de 1950, a jurisprudência da Suprema Corte americana tornou-se progressista na tutela dos direitos fundamentais, destacando-se os casos

\footnotetext{
7 "Art. 227. É dever da família, da sociedade e do Estado assegurar à criança, ao adolescente e ao jovem, com absoluta prioridade, o direito à vida, à saúde, à alimentação, à educação, ao lazer, à profissionalização, à cultura, à dignidade, ao respeito, à liberdade e à convivência familiar e comunitária, além de colocá-los a salvo de toda forma de negligência, discriminação, exploração, violência, crueldade e opressão".

8 "Poderão ser utilizados recursos federais, estaduais, distritais e municipais para a manutenção dos serviços de acolhimento em família acolhedora, facultando-se o repasse de recursos para a própria família acolhedora".
} 
envolvendo negros (Brown v. Board of Education, 1954), as mulheres (Frontiero v. Richardson, 1973), o direito de privacidade (Griswold v. Connecticut, 1965) e a interrupção da gestação (Roe v. Wade, 1973) (BARROSO, 2012, p. 23-32).

Verifica-se que o ativismo judicial é uma questão delicada e que ainda causa muita polêmica na doutrina, havendo vozes favoráveis e outras contrárias à sua compatibilidade com o ordenamento jurídico brasileiro.

Para aqueles que o enxergam de forma negativa, o Poder Judiciário extrapolaria as suas competências de resolver os conflitos de interesses e os conflitos normativos, imiscuindo-se em questões afetas a outros Poderes. Por tal concepção, entende-se por ativismo judicial

[...] o exercício da função jurisdicional para além dos limites impostos pelo próprio ordenamento que incumbe, institucionalmente, ao Poder Judiciário fazer atuar, resolvendo litígios de feições subjetivas (conflitos de interesse) e controvérsias jurídicas de natureza objetiva (conflitos normativos). Há, como visto, uma sinalização claramente negativa no tocante às práticas ativistas, por importarem na desnaturação da atividade típica do Poder Judiciário em detrimento dos demais Poderes. (RAMOS, 2015, p. 131).

Para os que veem o ativismo judicial como um fenômeno positivo, o Poder Judiciário, no limite de suas competências, mas com reflexos nas searas dos demais Poderes, ampliaria a interpretação da Constituição e garantiria a máxima efetividade do texto Constitucional. Nessa concepção, ativismo judicial

[...] é uma atitude, a escolha de um modo específico e proativo de interpretar a Constituição, expandindo o seu sentido e alcance [...] A idéia de ativismo judicial está associada a uma participação mais ampla e intensa do Judiciário na concretização dos valores e fins constitucionais, com maior interferência no espaço de atuação dos outros dois Poderes. (BARROSO, 2012, p. 23-32).

Independentemente da concepção negativa ou da positiva acerca do fenômeno ativismo judicial, há um ponto conceitual em comum entre elas, ao afirmarem que se trata de uma postura ativa do Poder Judiciário, concretizando direitos, em razão da inércia dos outros Poderes.

Entre os argumentos contrários ao ativismo judicial, destacam-se: I) afronta à Separação de Poderes com direta usurpação das funções da legislatura ou da autoridade administrativa (MORAES, 2012, p. 267-85); II) ausência de superação da teoria positivista (RAMOS, 2015, p. 57); III) no aspecto político-ideológico, o Poder Judiciário careceria de legitimidade democrática (NALINI, 2013, p. 388); IV) a invocação de um princípio constitucional não poderia servir de pretexto argumentativo para o Judiciário extravasar as suas competências (RAMOS, 2015, p. 254-71); V) cria-se o risco de uma sociedade puerilizada (NALINI, 2013, p. 388), transformandose o Poder Judiciário em superego da sociedade (MAUS, 2000, p. 183-202).

Pela relevância de cada um desses argumentos, passa-se a analisá-los separadamente. Frisase que a pretensão não é rechaçá-los, mas apresentar contrapontos, estabelecendo parâmetros à atuação judicial, de modo a construir caminhos à resolução de uma importante questão na tutela dos direitos da criança e do adolescente: a inércia do Poder Executivo na implantação de políticas públicas, mais especificamente, as famílias acolhedoras no Estado de Mato Grosso do Sul. 


\subsection{Violação à separação de poderes}

Tecem-se críticas ao ativismo judicial porque implicaria desrespeito à Separação de Poderes, ou seja, o Judiciário extrapolaria a sua competência para usurpar funções atribuídas aos demais Poderes (MORAES, 2012, p. 267-85). Contudo deve-se destacar que nenhum poder é absoluto, de modo que, em caso de não observância por um deles da Constituição, há meios de controle pelos outros Poderes.

Nesse sentido, frisa-se que a Separação de Poderes originou a construção doutrinária denominada sistema de freios e contrapesos, pelo qual "se houver a exorbitância de qualquer dos poderes surge a ação fiscalizadora do poder judiciário, obrigando cada um a permanecer nos limites de sua respectiva esfera de competência" (DALLARI, 2011, p. 218).

A doutrina constitucional contemporânea aponta duas ideias para lançar luzes sobre os limites da intervenção: a capacidade institucional e o risco de efeitos sistêmicos. Por meio da capacidade institucional, dever-se-ia prestigiar a decisão do Poder mais habilitado a produzir a melhor decisão por possuir mais informações técnicas ou científicas sobre o assunto. Com base no risco de efeitos sistêmicos, seria necessário reconhecer que o Judiciário é habilitado a decidir questões micro, não se encontrando sob a sua expertise a solução de questões macro, podendo colocar em risco uma determinada política pública. Ao final, conclui-se que o Judiciário quase sempre pode, mas nem sempre deve interferir (BARROSO, 2012, p. 23-32).

Entretanto tais ideias parecem criar um resultado contrário ao desejado, na medida em que deixariam direitos fundamentais desprotegidos, ao afirmarem que um Poder tem melhores condições de decidir acerca da concretização de direitos fundamentais. Pense-se, por exemplo, em políticas públicas sobre educação e saúde, em que o Poder Executivo, por possuir mais contato com as demandas, teria melhores condições de decidir, porém não o faz, violando direitos fundamentais. O Poder Judiciário poderia deixar de agir? Parece que não, sob pena de negar vigência ao direito fundamental invocado (no caso, a saúde), além da violação a outro direito fundamental - a inafastabilidade da jurisdição, prevista no artigo 5o, XXXV, da Constituição Federal.

Os limites à atuação dos poderes devem ser os próprios direitos fundamentais, explícitos ou implícitos, emanados do texto constitucional. Cabe a todo Poder reconhecê-los e garanti-los, sendo que, em caso de inércia ou negativa por um deles, competirá ao Poder Judiciário fazer cumpri-los. Percebe-se, portanto, que não está o Judiciário a invadir as funções constitucionais de outro Poder, mas atuar quando um dos Poderes deixar de respeitar os direitos fundamentais e, assim, a própria Constituição.

\subsection{Superação do positivismo jurídico}

A doutrina que rechaça o ativismo judicial alega que o positivismo jurídico continua sólido, não havendo que se falar em sua superação, conforme sustentam os chamados pós-positivistas (RAMOS, 2015, p. 57). Além da expressão pós-positivismo, surgem outros termos sinônimos para designar o protagonismo do Poder Judiciário, destacando-se neoconstitucionalismo, moralização, retorno dos valores ou constitucionalização do direito (DIMOULIS, 2011, p. 215-53).

Ao contrário do que sustenta parcela da doutrina, a defesa do ativismo judicial não se mostra incompatível com o positivismo jurídico, pois o que pretende o magistrado ativista é dar máxima efetividade ao texto constitucional e à legislação infraconstitucional diante da omissão dos demais Poderes. 
Não se pode olvidar que a norma não basta, por si só, para resolver todas as situações da vida em sociedade. Ela exige a atitude ativa do intérprete, aplicando, interpretando a norma geral, de modo a criar a norma para o caso concreto. Assim, a "norma fundamental não exclui a possibilidade de o juiz agir aplicando e interpretando, ou seja, produzindo normas individuais" (BITTAR, 2019, p. 432).

Deve ficar claro que o Poder Judiciário não atua de ofício, criando leis e implementando políticas públicas. Todas as ações do Poder Judiciário, com a pecha ou não de ativistas, são provocadas pelas partes, por meio de um devido processo legal, encontrando respaldo a pretensão na própria Constituição Federal, ao afirmar, em seu artigo 5, inciso XXXV, que "a lei não excluirá da apreciação do Poder Judiciário lesão ou ameaça a direito".

É interessante observar que uma das hipóteses em que o Poder Judiciário é criticado por seu ativismo diz respeito às súmulas vinculantes, pois, ao editá-las, o Supremo Tribunal Federal exerceria competência legislativa (NERY JÚNIOR; ABBOUD, 2013, p. 2013). Contudo não se pode aceitar tal alegação, já que foi o próprio Poder Executivo que, alterando o texto constitucional (art. 103-A), outorgou competência ao Poder Judiciário para a edição de súmulas vinculantes?

O Poder Judiciário, quando age nos limites permitidos pela Constituição Federal de 1988, está simplesmente exercendo a sua competência constitucional. Ainda que a competência seja aprioristicamente pertencente a outro Poder, a sua inércia desafia a competência constitucional de agir ao Judiciário, conforme artigo 5ㅇ, XXXV, da CF/1988. Se o Judiciário está a agir respaldado pela própria Constituição Federal, não há negação alguma ao positivismo jurídico, mas apenas o cumprimento da Constituição.

\subsection{Ausência de legitimidade democrática do Judiciário}

Outra crítica comumente realizada ao ativismo judicial é que o Poder Judiciário, ao contrário dos Poderes Executivo e Legislativo, não gozaria de legitimidade democrática, já que os seus membros não foram escolhidos pelo voto popular (NALINI, 2013, p. 386). Entretanto tal concepção também não deve prosperar.

Verifica-se que a própria Constituição Federal, aprovada pelos representantes eleitos pelo povo, outorgou competência ao Poder Judiciário, em seus artigos 92 a 126, para a aplicação da Constituição e das leis. Ainda, deve-se destacar que a Constituição Federal, além de estabelecer as regras do jogo democrático, a partir de ampla participação política (princípio majoritário), comprometeu-se a proteger direitos e garantias fundamentais, mesmo contra a vontade da maioria (princípio contramajoritário) (BARROSO, 2012, p. 23-32). Também não se pode olvidar que, quando os demais poderes perdem a sua legitimidade democrática, mantendo-se inertes perante os problemas sociais e deixando de garantir os direitos fundamentais, o Poder Judiciário não agirá como usurpador de competência, mas exercerá o seu papel constitucional de preencher vazios normativos e dar a resposta almejada pela população (DIMOULIS, 2011, p. 215-53).

Dessa forma, por qualquer viés, a fundamentação da legitimidade democrática do Poder Judiciário é encontrada na própria Constituição Federal, que é fruto da soberania popular.

\footnotetext{
9 "Na verdade, porém, por mais que a edição de súmula vinculante é atividade que se assemelhe materialmente à legislação, a previsão constitucional da edição de súmula vinculante torna-a competência legítima do Judiciário. Nesse caso, o Poder Judiciário cumpre sua tarefa desde que atue nos limites de sua competência" (DIMOULIS, 2011).
} 


\subsection{Os princípios e a discricionariedade do julgador}

Assegura parcela da doutrina que um princípio constitucional não pode servir de pretexto para que o Judiciário extravase as suas competências e defina, discricionariamente, o nível de eficácia das normas constitucionais (RAMOS, 2015, p. 254-71). A afirmação, contudo, merece algumas considerações.

A primeira observação é que o Poder Judiciário não poderá extravasar a sua competência, pois essa é delimitada constitucionalmente. Somente é permitido ao Judiciário imiscuir-se em atribuições de outros Poderes, quando esses permanecerem inertes, descumprindo as normas constitucionais, o que justifica a intervenção em razão do princípio constitucional da inafastabilidade da jurisdição.

A segunda observação se refere à natureza jurídica dos princípios. Eles não trazem consigo conteúdos inúteis, criados para ornarem a constituição ou as leis infraconstitucionais, mas são norma ${ }^{10}$ e, como tal,

[...] não possui somente um sentido, mas vários possíveis. A ciência do direito procura somente identificar e descrever esses possíveis sentidos. As muitas possibilidades jurídicas facultam muitas escolhas, e é nisso que reside a liberdade do juiz, ou seja, no poder de determinar qual dos sentidos é o mais adequado para o caso concreto. (BITTAR; ALMEIDA, 2019, p. 433).

Por se tratar de uma norma, dotada de múltiplos sentidos possíveis, caberá ao intérprete delimitá-la, o que será feito não de forma arbitrária, mas fundamentada por meio da linguagem ${ }^{11}$. A interpretação e a fundamentação, exteriorizadas pelo magistrado por meio da linguagem, são as formas legítimas de controle das decisões judiciais ${ }^{12}$.

Por fim, uma última observação se mostra pertinente sobre o nível de eficácia das normas constitucionais e o papel do magistrado na sua implementação. É preciso destacar que as disposições constitucionais não são uma simples folha de papel (LASSALLE, 2012, p. 27). Elas "não são meras exortações ou conselhos - de simples valor moral. Todas elas são - inclusive as programáticas - comandos jurídicos e, por isso, obrigatórias, gerando para o Estado deveres de fazer ou não-fazer" (BANDEIRA DE MELLO, 2009, p. 54). É por essa razão que o magistrado não tem a faculdade de deixar de aplicar uma norma constitucional, ainda que programática,

\footnotetext{
${ }^{10}$ Os princípios têm os seguintes elementos: - caráter normativo: os princípios são normas; - caráter inacabado: são normas prima facie sem uma terminação acabada, e por isso suscetíveis de serem completadas; - caráter valorativo: os princípios são normas que recepcionam valores e, portanto, variam conforme os sistemas jurídicos, o momento histórico e a relação com as regras; - caráter excessivo: por veicular expressão abrangente, os princípios colidem com outros princípios, outros valores ou outros direitos, sendo necessário medi-los, estabelecer sua relação com outros princípios e regras de modo a obter um conteúdo; - mandado de otimização: estabelecem os princípios uma direção que deve ser cumprida na maior proporção possível. A sua aplicação implica estabelecer uma relação com outros princípios concorrentes ou contraditórios, cabendo ao intérprete alcançar o ponto ótimo de realização (LORENZETTI, 2010, p. 125-6).

11 "Gli elementi che concorrono a rendere impossibile la riduzione del giudice a 'bocca della legge' sono il linguaggio, costituente l'indispensabile strumento per la formulazione delle leggi e delle sentenze, e la natura delle seconde. A proposito del linguaggio esiste un comune consenso sul duplice fatto che ogni testo - compreso quello che enuncia una regola giuridica - è suscettibile di varia interpretazione e che le parole tendono nel tempo a mutare significato" (GALLO, 2014, p. 47).

12 "[...] o direito autoritário, aquele que se impõe pelo respeito e pela majestade, não precisa motivar. Aquele que se quer democrático, obra de persuasão e de razão, deve procurar, pela motivação, obter uma adesão arrazoada" (PERELMAN, 2005, p. 570).
} 
pois inclusive elas têm força normativa ${ }^{13}$, cabendo ao intérprete buscar a sua máxima eficácia na análise do caso concreto.

\subsection{O risco de uma sociedade puerilizada e o Poder Judiciário como superego da sociedade}

Outra crítica ao ativismo judicial é o risco de se criar uma sociedade puerilizada, em que todas as suas questões sejam decididas pelo Poder Judiciário, tolhendo da população uma formação para a cidadania participativa e deixando-a incapaz de resolver os seus próprios problemas (NALINI, 2013, p. 388).

No mesmo sentido, Ingeborg Maus (2000), professora da Universidade Johann Wolfgang Goethe, invoca conceitos psicanalíticos para criticar o ativismo judicial. Em sua concepção, o Poder Judiciário, com sua postura ativista, acaba por deixar a "sociedade órfã", incapaz de resolver os seus problemas, transformando o Judiciário em seu "superego", a quem cabe dizer o que é certo ou errado, justo ou injusto, tornando-se a sua instância moral, sem qualquer controle social.

A partir dos argumentos supracitados, não se desconsidera que a transferência de expectativas da população ao Judiciário e a inércia dos demais Poderes em cumprirem suas missões constitucionais podem gerar uma perniciosa situação de passividade, fragilizando a Democracia Participativa e retirando legitimidade dos Poderes Executivo e Legislativo.

Entretanto é verdade também que o Poder Judiciário não pode, a pretexto de exercer um papel pedagógico, manter-se omisso diante do descumprimento de preceitos constitucionais e infraconstitucionais, sob pena de negar vigência à sua competência constitucional.

Talvez a solução seja, sem negar ao Poder Judiciário o seu dever de cumprimento da prestação jurisdicional, promover a conscientização da população, por meio da educação, acerca da importância de sua participação na vida do Estado, cobrando posturas ativas dos parlamentares e dos membros do Executivo na concretização dos direitos. É importante que a sociedade tenha a convicção de que a sua passividade conduz à morosidade na realização de direitos, seja pela cômoda inércia dos Poderes Executivo e Legislativo, seja pelo abarrotamento de processos sob a apreciação do Poder Judiciário.

\section{INÉRCIA MUNICIPAL NA IMPLANTAÇÃO DO PROGRAMA DE ACOLHIMENTO FAMILIAR NO ESTADO DE MATO GROSSO DO SUL: CAMINHOS POSSÍVEIS}

O Estado de Mato Grosso do Sul atualmente é composto por 79 municípios ${ }^{14}$, sendo que apenas 10 deles têm o Programa Família Acolhedora implantado ou em fase de implantação: Campo Grande, Camapuã, Ponta Porã, Laguna Carapã, Mundo Novo, Sete Quedas, Paranhos, Coxim, Alcinópolis e Ribas do Rio Pardo ${ }^{15}$.

A partir da análise dos dados, observa-se que o Programa Família Acolhedora foi previsto no artigo 34 do Estatuto da Criança e do Adolescente, no ano de 2009, por meio da Lei n. 12.010, porém, até o momento, apenas $12,65 \%$ dos municípios cumpriram a determinação legal.

\footnotetext{
${ }^{13}$ Vale destacar a advertência de que "um ótimo desenvolvimento da força normativa da Constituição depende não apenas do seu conteúdo, mas também de sua práxis. De todos os partícipes da vida constitucional, exige-se partilhar aquela concepção por mim denominada vontade de Constituição (Wille zur Verfassung)" (HESSE, 1991, p. 21).

${ }^{14}$ Disponível em: http://www.semagro.ms.gov.br/wp-content/uploads/2018/12/Perfil-Estatístico-de-MS-2018.pdf. Acesso em: 26 jul. 2019.

${ }^{15}$ Disponível em: https://www.tjms.jus.br/projetos/projeto_familia_acolhedora.php. Acesso em: 26 jul. 2019.
} 
Diante da inércia do Poder Executivo municipal de aproximadamente 10 anos na implementação de uma relevante política pública para a proteção de crianças e adolescentes em situação de vulnerabilidade social, é preciso que se indague quais seriam os caminhos possíveis.

A primeira possibilidade é a autocontenção judicial, conduta por meio da qual o Poder Judiciário objetiva reduzir a sua interferência nas ações dos demais poderes (BARROSO, 2012, p. 23-32). No presente caso, em se tratando da concretização de uma política pública, o Judiciário se absteria de interferir em sua definição, deixando a cargo do Poder Executivo implementá-la como e quando bem entendesse.

A autocontenção judicial foi a inequívoca linha de atuação do Poder Judiciário brasileiro antes do advento da Constituição Federal de 1988 (BARROSO, 2012, p. 23-32). Contudo não parece estar em sintonia com os compromissos assumidos pela Constituição Federal atual, garantidora de um amplo rol de direitos fundamentais, que necessitam de concretização.

A segunda possibilidade é o Poder Judiciário reconhecer a violação a direitos fundamentais e impor ao Poder omisso um plano de ação para fazer cessar a ofensa. Tal plano seria discutido em audiência, com uma ampla participação dos interessados, cabendo ao magistrado decidir, ao final, o modo como as políticas públicas seriam implementadas (JORGE NETO, 2009, p. 155-7).

Tal proposta mostra-se interessante na medida em que permite ao Poder omisso trazer ao debate elementos desconhecidos pelo magistrado, tais como tempo de execução e disponibilidade orçamentária. Contudo, para os críticos do ativismo judicial, ainda reserva ao Judiciário dar a última palavra na execução da política pública. Um ponto fraco dessa proposta é a possibilidade de o Poder omisso ainda manter-se inerte, mesmo com a determinação judicial.

Surge daí uma terceira possibilidade, em que o Poder Judiciário reconhece a violação a direitos fundamentais e determina que a omissão seja sanada, comunicando-se ao Poder omisso. Nesse caso, caberá a tal Poder dar a última palavra, já que goza da representatividade popular. Essa foi a tese sustentada pelo professor espanhol Sebastián Linares, ao afirmar que:

[...] Defendí en cambio una propuesta alternativa que confiere a los jueces inferiores la potestad de declarar la incompatibilidad de las leyes contemporáneas (sin efectos invalidantes); otorga a la Corte Suprema la potestad de invalidar las leyes contemporáneas y, finalmente, concede al Congreso la posibilidad de emplear una cláusula de override para hacer prevalecer su voluntad frente a una sentencia adversa de la Corte. Con algunos matices adicionales, sostuve que un modelo así ofrece un margen mayor para la formación de un diálogo interorgánico con credenciales democráticas. (LINARES, 2008, p. 305).

O problema em relação à referida tese é que o Poder Judiciário funciona como mero comunicante acerca de uma inconstitucionalidade ou omissão na implementação de uma política pública, não podendo decidir em caso de inércia. Parece violar o sistema de freios e contrapesos (DALLARI, 2011, p. 218) na medida em que será o mesmo Poder omisso quem decidirá acerca da subsistência de sua omissão, correndo-se o risco do surgimento de um superpoder.

A quarta possibilidade seria o Poder Judiciário reconhecer a violação aos direitos fundamentais e determinar que o Poder omisso faça cessar a ofensa, implementando a política pública vindicada, em um prazo determinado, além de fixar astreintes ${ }^{16}$ em caso de descumprimento. Esse parece ser o caminho mais utilizado pelos tribunais brasileiros atualmente ${ }^{17}$.

\footnotetext{
${ }^{16}$ Ver previsão expressa de fixação de astreintes nos seguintes dispositivos legais: art. 461 do CPC/1973, art. 536, $\S 10$, CPC/15; art. 84, CDC; art. 11 da Lei 7.347/85.

17 “A Primeira Seção do STJ referendou o entendimento, no REsp Repetitivo 1.474.665/RS (Relator Ministro Benedito
} 
Apesar de um provável respeito à Separação de Poderes na medida em que o Poder Judiciário impõe que o Poder omisso concretize a ação de sua competência, poder-se-ia alegar que o Judiciário é quem acaba dando a última palavra, fixando prazos e condições, usurpando competência de outro Poder. Além disso, tal caminho apresentaria uma fragilidade, já que o Poder omisso poderá, mesmo com determinação judicial e arbitramento de astreintes, descumprir a ordem judicial.

Por fim, surge uma quinta possibilidade. Em caso de inércia de um dos Poderes na efetivação dos direitos fundamentais, mesmo após o arbitramento de astreintes, o Poder Judiciário concretiza diretamente o direito fundamental violado. Isso se dá por meio do bloqueio de verbas públicas, realizado pelo Sistema Bacenjud, além de outras medidas que o magistrado julgar necessárias.

Em algumas situações extremas de violação a direitos fundamentais, o Poder Judiciário já tem se valido dessa medida, tal como ocorre na negativa do poder público na concessão de medicamentos ou tratamentos médicos, autorizando o bloqueio judicial para o custeio do restabelecimento da saúde da população:

1. Tratando-se de fornecimento de medicamentos, cabe ao Juiz adotar medidas eficazes à efetivação de suas decisões, podendo, se necessário, determinar até mesmo, o sequestro de valores do devedor (bloqueio), segundo o seu prudente arbítrio, e sempre com adequada fundamentação.

2. Recurso Especial provido. Acórdão submetido ao regime do art. 543-C do CPC e da Resolução 08/2008 do STJ. (BRASIL, 2013 , p. 1).

Além de uma forte ingerência do Poder Judiciário no âmbito de competência de outros Poderes, inclusive com uma medida extrema do bloqueio de verbas públicas, a opção por tal via apresenta maiores dificuldades no momento de concretização de outros direitos fundamentais, tais como construção de creches, escolas, hospitais etc. Embora esteja agindo na tutela dos direitos fundamentais, tal medida implica trazer para o Poder Judiciário questões totalmente estranhas ao âmbito de sua competência ordinária (contratação de empreiteira, pagamentos, aquisição de materiais etc.).

Diante dos fundamentos favoráveis e contrários ao ativismo judicial, em havendo provocação por eventuais legitimados ${ }^{18}$, propõe-se que o Poder Judiciário deva agir da seguinte forma para a garantia da concretização do Programa Família Acolhedora em cada um dos municípios do Estado de Mato Grosso do Sul:

a) designar audiência de conciliação, determinando-se que a municipalidade apresente um plano de ação (JORGE NETO, 2009, p. 155-57), detalhando a forma de implementação e os recursos orçamentários necessários. Caso haja uma efetiva proposta de implementação, o magistrado homologará o acordo;

b) caso subsista a inércia, deixando o município de apresentar um plano de ação, caberá ao magistrado compeli-lo a fazer, fixando prazo e estabelecendo astreintes;

Gonçalves), de que a imputação de multa pela desobediência à obrigação de fazer ou de não fazer, inclusive contra o Estado, decorre do 'poder geral de efetivação', concedido ao juiz para fazer valer, no mundo dos fatos, as suas decisões. Precedentes: REsp 1.499.927/DF, Rel. Ministro Humberto Martins, Segunda Turma, julgado em 17/12/2015, DJe 5/2/2016; REsp 947.555/MG, Rel. Ministro Herman Benjamin, Segunda Turma, julgado em 18/8/2009, DJe 27/4/2011; REsp 1.184.194/RS, Rel. Ministra Eliana Calmon, Segunda Turma, julgado em 2/9/2010, DJe 22/9/2010" (BRASIL, 2018).

${ }^{18}$ Ver o rol de legitimados ao ajuizamento da ação civil pública no artigo 5o da Lei n. 7.347/1985. 
c) mesmo com a fixação de astreintes, é possível que a municipalidade ainda assim se mantenha inerte. Nesse caso, não restará ao Poder Judiciário outra śaída que não seja a implementação da política pública. Poderá valer-se da própria equipe técnica do Poder Judiciário para realizar a seleção, a capacitação e o acompanhamento das famílias acolhedoras. Caso não tenha equipe técnica disponível, a nomeação de profissionais fora dos quadros poderá ser uma alternativa, aplicando-se o artigo 151, parágrafo único, do Estatuto da Criança e do Adolescente. Por meio do sequestro de verbas públicas, poderá o magistrado autorizar a remuneração das famílias acolhedoras.

Ao arremate, deve-se destacar que o Poder Judiciário, como regra, não deve imiscuir-se nas competências inerentes aos demais Poderes, sob pena de violação ao princípio da Separação de Poderes. Todavia, se persistir a violação a direitos fundamentais, como tem ocorrido com a implantação do Programa Família Acolhedora nos municípios sul-mato-grossenses, deverá o Poder Judiciário agir, sob pena de chancelar uma cultura de ineficácia do texto constitucional e descumprimento das normas infraconstitucionais.

\section{CONSIDERAÇÕES FINAIS}

O Programa Família Acolhedora foi expressamente previsto no Estatuto da Criança e do Adolescente, por meio da Lei n. 12.010, de 3 de agosto de 2009, impondo ao Poder Executivo a sua implementação como política pública, prestigiando o acolhimento familiar em detrimento do acolhimento institucional. Entretanto, transcorridos aproximadamente 10 anos de sua vigência, a lei não surtiu o efeito desejado. No Estado de Mato Grosso do Sul, por exemplo, entre os 79 municípios, apenas 10 o implementaram ou estão em vias de implementação, o que corresponde a apenas $12,65 \%$ dos municípios sul-mato-grossenses.

Diante da inércia do Poder Executivo em realizar a sua missão constitucional de tratar a infância e a juventude com absoluta prioridade (Art. 227, CF/1988), foram apresentadas indagações acerca de como o Poder Judiciário poderia adentrar na esfera de competência de outro Poder para assegurar disposições constitucionais e infraconstitucionais, além das formas de materialização de tal ingerência e de seus limites. Em relação ao caso do Programa Família Acolhedora no Estado de Mato Grosso do Sul, foi indagado como poderia o Poder Judiciário garantir a sua efetivação.

Para responder aos citados questionamentos, foram apresentados inicialmente os argumentos contrários ao ativismo judicial, destacando-se: I) que a intervenção do Poder Judiciário na esfera de competência de outros poderes implica violação ao Princípio da Separação de Poderes, usurpando-se competências que não são suas; II) o papel do Judiciário em extrapolar a Constituição e as leis, fazendo aquilo que não está previsto nas normas, implica violação ao positivismo jurídico, que, ao contrário do que sustentam os chamados pós-positivistas ou neoconstitucionalistas, ainda continua sólido; III) alega-se também que o Poder Judiciário não goza de legitimidade democrática, já que os seus membros não foram escolhidos pelo povo, ao contrário do que ocorre nos demais Poderes; IV) diz-se que o Poder Judiciário invoca princípios constitucionais como pretexto argumentativo para usurpar competências alheias; V) por fim, alega-se que o ativismo judicial cria o risco de construir uma sociedade puerilizada, que tem o seu superego - sua instância moral - centrado no Poder Judiciário, sem controle social algum.

Na sequência, foram rebatidos os argumentos contrários à postura ativista com os seguintes fundamentos: I) não há que se falar em violação à Separação dos Poderes, quando a própria 
Constituição Federal delimita a competência do Poder Judiciário e autoriza a agi-lo em casos de lesão ou ameaça concreta de lesão a direitos; II) se há dispositivos constitucionais autorizando o Poder Judiciário a agir, não há negação do Positivismo Jurídico. Um dos exemplos mais utilizados para se criticar o ativismo é a edição de súmulas vinculantes, que são autorizadas expressamente pelo artigo 103-A da CF; III) quanto à suposta ausência de legitimidade democrática ao Poder Judiciário, destacou-se que a sua competência de agir está prevista na Constituição, que é fruto da soberania popular. Além disso, quando há perda de legitimidade dos demais Poderes, compete ao Judiciário preencher os vazios normativos, cumprindo sua missão de tutela dos direitos fundamentais; IV) no tocante à alegação de que o Judiciário se vale de princípios constitucionais para usurpar competência de outros Poderes, deve-se recordar que os princípios são normas e, como tais, possuem densidade normativa, inclusive aquelas de caráter programático, cabendo ao magistrado buscar a sua máxima eficácia no caso concreto. A interpretação e a fundamentação, por meio da linguagem, são os mecanismos de controle social da decisão judicial; V) destacou-se que, mesmo se correndo o risco de construir uma sociedade infantilizada, que tem no Judiciário o seu superego, não pode o Judiciário, a pretexto de exercer um papel educativo, deixar de tutelar direitos fundamentais violados, cabendo investir em educação como forma de incentivo à Democracia Participativa.

Ao final, diante da inércia do Poder Executivo na implementação do Programa Família Acolhedora nos municípios do Estado de Mato Grosso do Sul, apresentaram-se as seguintes propostas: - determinar que o município inerte apresente um plano de ação, especificando prazos e formas de implementação; - em caso de descumprimento, arbitrar astreintes como forma de compeli-lo; - caso ainda permaneça a omissão, o único caminho possível seria o próprio Poder Judiciário implementar o programa, às expensas do Poder Executivo, sob pena de negativa de vigência ao princípio constitucional da absoluta prioridade da infância e da adolescência, além de violar o próprio Estatuto da Criança e do Adolescente, que sufragou a Família Acolhedora como relevante política pública em favor de crianças e adolescentes em situação de vulnerabilidade social.

\section{REFERÊNCIAS}

BANDEIRA DE MELLO, Celso Antônio. Eficácia das normas constitucionais e direitos sociais. São Paulo: Malheiros, 2009.

BARROSO, Luís Roberto. Judicialização, ativismo judicial e legitimidade democrática. Revista Thesis, Rio de Janeiro, v. 5, n. 1, p. 23-2, 2012.

BITTAR, Eduardo Carlos Bianca; ALMEIDA, Guilherme Assis de. Curso de filosofia do direito. 14. ed. São Paulo: Atlas, 2019.

BRASIL. Recurso Especial provido. Acórdão submetido ao regime do art. 543-C do CPC e da Resolução 08/2008 do STJ. Disponível em: file:///C:/Users/canut/Downloads/3652-13724-1-PB.pdf. Acesso em: 25 out. 2020.

BRASIL. Lei n. 12.010, de 3 de agosto de 2009. Dispõe sobre adoção; altera as Leis nos 8.069, de 13 de julho de 1990- Estatuto da Criança e do Adolescente, 8.560, de 29 de dezembro de 1992; revoga dispositivos da Lei no 10.406, de 10 de janeiro de 2002 - Código Civil, e da Consolidação das Leis do Trabalho - CLT, aprovada pelo Decreto-Lei no 5.452, de 10 de maio de 1943; e dá outras providências. Disponível em: http://www.planalto.gov.br/ccivil_03/_ato2007-2010/2009/lei/l12010.htm\#: :text=10\%20Esta\%20Lei\%20 disp\%C3\%B5e,da\%20Crian\%C3\%A7a\%20e\%20do\%20Adolescente. Acesso em: 25 out. 2020. 
BRASIL. Superior Tribunal de Justiça. REsp 1723590/RJ, Rel. Ministro Herman Benjamin, segunda turma, julgado em 08/05/2018, DJe 26/11/2018. Brasília-DF, 2018.

DALLARI, Dalmo de Abreu. Elementos de teoria geral do Estado. 30. ed. São Paulo: Saraiva, 2011.

DIMOULIS, Dimitri. A relevância prática do positivismo jurídico. Revista Brasileira de Estudos Políticos, Belo Horizonte, n. 102, p. 215-53, jan./jun. 2011.

GALLO, Filippo. Carattere ideologico della soggezione del giudice alla legge. Turim: G. Giappichelli Editore, 2014.

HESSE, Konrad. A força normativa da constituição. Tradução Gilmar Ferreira Mendes. Porto Alegre: Sérgio Antonio Fabris Editor, 1991.

JORGE NETO, Nagibe de Melo. O controle jurisdicional das políticas públicas: concretizando a democracia e os direitos sociais fundamentais. Salvador: Juspodivm, 2009.

KREUZ, Sergio Luiz. Direito à convivência familiar da criança e do adolescente: direitos fundamentais, princípios constitucionais e alternativas ao acolhimento institucional. Curitiba: Juruá, 2012.

LASSALLE, Ferdinand. O que é uma Constituição? Leme-SP: Edijur, 2012.

LÉPORE, Paulo Eduardo; ROSSATO, Luciano Alves; CUNHA, Rogério Sanches. Estatuto da Criança e do Adolescente: Lei 8.069/90 - comentado artigo por artigo. 10. ed. São Paulo: Saraiva Educação, 2018.

LINARES, Sebastián. La (i)legitimidad democrática del control judicial de las leyes. Madri: Marcial Pons, 2008.

LORENZETTI, Ricardo Luis. Teoria da decisão judicial: fundamentos de direito. Tradução: Bruno Miragem. Notas: Cláudia Lima Marques. 2. ed. São Paulo: Editora Revista dos Tribunais, 2010.

MAUS, Ingeborg. Judiciário como superego da sociedade. O papel da atividade jurisprudencial na "sociedade órfã". Tradução de Martonio Lima e Paulo Albuquerque. Revista Novos Estudos CEBRAP, n. 58, p. 183-202, 2000.

MORAES, Alexandre de. As súmulas vinculantes no Brasil e a necessidade de limites ao ativismo judicial. Revista da Faculdade de Direito da Universidade de São Paulo, São Paulo, v. 106/107, p. 267-85, 2012.

NALINI, José Renato. Ativismo judicial, garantismo ou produtividade adequada? In: DIDIER JÚNIOR, Fredie et al. Ativismo judicial e garantismo processual. Salvador: Juspodivm, 2013. p. 386-8.

NERY JÚNIOR, Nelson; ABBOUD, Georges. Ativismo judicial como conceito natimorto para consolidação do Estado Democrático de Direito: as razões pelas quais a justiça não pode ser medida pela vontade de alguém. In: DIDIER JÚNIOR, Fredie et al. Ativismo judicial e garantismo processual. Salvador: Juspodivm, 2013, [s.p.].

PERELMAN, Chaïm. Ética e direito. Tradução de Maria Ermantina de Almeida Prado Galvão. São Paulo: Martins Fontes, 2005.

RAMOS, Elival da Silva. Ativismo judicial: parâmetros dogmáticos. 2. ed. São Paulo: Saraiva, 2015. VALENTE, Jane. Família acolhedora: as relações de cuidado e de proteção no serviço de acolhimento. São Paulo: Paulus, 2013. 


\section{Sobre os autores:}

Michel Canuto de Sena: Doutorando em Saúde e Desenvolvimento da Região Centro-Oeste na Universidade Federal de Mato Grosso do Sul (UFMS). Mestre em Ciências Farmacêuticas pela UFMS. Especialista em Direito Civil e Processo Civil pela Universidade Católica Dom Bosco (UCDB). Graduado em Direito pela Faculdade Mato Grosso do Sul (Facsul). Professor de Bioética e Direito Civil na UFMS. E-mail: michel.canuto.sena@gmail.com, Orcid: http://orcid.org/0000-0001-5317-2306

Fernando Moreira Freitas da Silva: Doutorando em Direito do Estado na Universidade de São Paulo (USP). Mestre em Direito Negocial pela Universidade Estadual de Londrina (UEL). Juiz de Direito do Tribunal de Justiça do Estado de Mato Grosso do Sul e professor da Escola da Magistratura de Mato Grosso do Sul. E-mail: fernandomoreira2103@gmail.com, Orcid: https://orcid.org/0000-0002-8503-5389

Heitor Romero Marques: Doutor em Desarrollo Local y Planteamiento Territorial pela Universidad Complutense de Madrid. Mestre em Educação e Formação de Professores pela Universidade Católica Dom Bosco (UCDB). Especialista em Filosofia e História da Educação pelas Faculdades Unidas Católicas de Mato Grosso (FUCMT). Professor do Programa de Mestrado e Doutorado em Desenvolvimento Regional da UCDB. E-mail: heiroma@ucdb.br, Orcid: https://orcid.org/0000-0003-0093-1617

Paulo Roberto Haidamus de Oliveira Bastos: Doutor e mestre em Educação pela Pontifícia Universidade Católica de São Paulo (PUC-SP). Professor titular (full professor) da Universidade Federal de Mato Grosso do Sul (UFMS). Professor visitante (visiting researcher) do Programa de Pós-Graduação Stricto Sensu em Saúde e Desenvolvimento na Região Centro-Oeste. E-mail: phaidamus43@gmail.com, Orcid: https://orcid.org/0000-0002-1276-0301 
